\title{
有限変形法による吊橋の解法* \\ FINITE DEFORMATION METHOD FOR SUSPENSION BRIDGES
}

\section{1. 緒言}

本理論は, 吊橋の静力学的な解析に, 有限変形法を応 用したもので，垂直荷重の作用する，あらゆる形式の吊 橋, 横荷重をうける連続あるいは不連続吊橋, および橋 軸方向へ変形を生ずる主塔の解析法について説明したも のである。

一般に，垂直荷重載荷の場合には，主ケーブルの垂直 変位のみを考慮した, 微分方程式による暁度理論 ${ }^{1}$ が用 いられていた。しかし,この方法では, 補剛げたや主ケー ブル節点の水平変位は計算できず, 本当の意味での厳密 解とはいいがたい。また，斜吊材など不規則吊材を有す る吊橋に対しては, 特別の考慮が必要であり, 計算不可 能となる場合が多い。また，通常の微小変形理論による 変形法を用いて解析することも考えられるが，この場合 には不規則吊材の有無, 外的不静定次数の増加などによ る難易はなくなるが, 各節点の変位量を逐次修正して, くり返し計算を必要とし, 線型化することはできない。

これらの難点は, 筆者の提唱する有限変形法によれば すべて解決されることになる。

すなわち, 変形法の利点はそのままに, 厳密解は仮定 張力を修正することで与えられ，またこれを一定とする ことで線型化された接度理論と対応し, 影響線を求める こともできる。

これは, 通常の変形法では, 死荷重による主ケーブル 張力が, 活荷重張力上りはるかに大きい長大吊橋の場合 でさえ, くり返し計算が必要であるのに対し, もっとも いちじるしい特徴である。

つぎに, 横荷重を受ける吊橋については, 従来, 補剛 げたと主ケーブルのそれぞれの分担荷重をくり返し計算 で求める方法 ${ }^{2)}$, 差分方程式による方法 ${ }^{3)}$, 多元連立方程 式による方法などが用いられている。

ここで, 筆者が述べる方法は, 主塔の場合も同様であ るが, 有限変形法の最も単純な応用の行列による解法で ある。

本法によれば, 解式が簡単明解で, 連続吊橋など適用 範囲が広く, 線型計算で簡単に影響線を求めることがで きる。

* 第 11 回橋梁, 楧造工学研究発表会にて一部発表

** 正会員 (株) 宮地鉄工所設計部

\begin{tabular}{|c|c|}
\hline By & Shigeo \\
\hline
\end{tabular}

なお，本理論の一部はすでに，文献)で発表したが， その中で，第二変形法と称していたものを有限変形法と あらため, 吊材の変形の影響もとりいれ, 横荷重を受け る場合と主塔への応用とともに, ここにあらためて発表 するものである。

\section{2. 垂直荷重を受ける任意形式の吊橋}

\section{（1）軸力部材における有限変形法の基本式}

軸力部材 $i j$ の両端の座標を $\left(u_{i}, v_{i}\right),\left(u_{j}, v_{j}\right)$ とする $\bar{N}_{i j}$ は, 死荷重などによる初期張力で, 変形前の状態で は，すでにつり合っているものである。これに活荷重が 加わり, 温度変化 $\left(+t^{\circ} \mathrm{C}\right)$ が生じて, $i j$ は, 図のよう に $i^{\prime} j^{\prime}$ と変位し, 張力が $\bar{N}_{i j}$ から $\bar{N}_{i j}+N_{i j}$ と変化 した場合を考える。

\section{図-1}

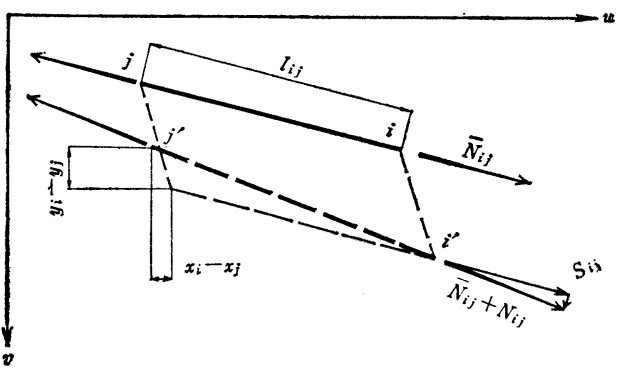

原材軸 $\overrightarrow{j i}$ の $u$ および $v$ 軸に対する方向余弦は，

$$
\alpha_{i j}=\frac{u_{i}-u_{j}}{l_{i j}}, \beta_{i j}=\frac{v_{i}-v_{j}}{l_{i j}}
$$

と表わされる。また変形後の材軸の方向余弦を

$$
\alpha_{i j}+\Delta \alpha_{i j}, \quad \beta_{i j}+\Delta \beta_{i j}
$$

とおき, $\Delta \alpha_{i j}$ および $\Delta \beta_{i j}$ を $\alpha_{i j}, \beta_{i j}$ の微分と考えて 求めれば, 変位の 2 次以上の項を省略した值が得られ る。

すなわち $, i, j$ 点の変位を $x_{i}, y_{i}$ および $x_{j}, y_{j}$ とす れば,

$$
\begin{aligned}
& \Delta \alpha_{i j}=\Delta\left(\frac{u_{i}-u_{j}}{l_{i j}}\right)=\frac{l_{i j} \cdot \Delta\left(u_{i}-u_{j}\right)-\left(u_{i}-u_{j}\right) \cdot \Delta l_{i j}}{l^{2}{ }_{i j}} \\
& \begin{aligned}
\Delta l_{i j} & =\Delta \sqrt{\left(u_{i}-u_{j}\right)^{2}+\left(v_{i}-v_{j}\right)^{2}} \\
& =\frac{1}{2} \frac{2\left(u_{i}-u_{j}\right)\left(x_{i}-x_{j}\right)+2\left(v_{i}-v_{j}\right)\left(y_{i}-y_{j}\right)}{\sqrt{\left(u_{i}-u_{j}\right)^{2}+\left(v_{i}-v_{j}\right)^{2}}} \\
& =\alpha_{i j}\left(x_{i}-x_{j}\right)+\beta_{i j}\left(y_{i}-y_{j}\right)
\end{aligned}
\end{aligned}
$$


$\therefore \Delta \alpha_{i j}=\beta^{2}{ }_{i j} \frac{x_{i}-x_{j}}{l_{i j}}-\alpha_{i j} \beta_{i j} \frac{y_{i}-y_{j}}{l_{i j}}$

同様に

$$
\Delta \beta_{i j}=-\alpha_{i j} \beta_{i j} \frac{x_{i}-x_{j}}{l_{i j}}+\alpha^{2}{ }_{i j} \frac{y_{i}-y_{j}}{l_{i j}}
$$

したがって, 変形後において, つり合いを考えなけれ ばならない軸力の $u, v$ 成分は,

$$
\begin{aligned}
X_{i j} & =\left(\alpha_{i j}+\Delta \alpha_{i j}\right)\left(\bar{N}_{i j}+N_{i j}\right)-\alpha_{i j} \bar{N}_{i j} \\
& =\alpha_{i j} N_{i j}+\Delta \alpha_{i j}\left(\bar{N}_{i j}+N_{i j}\right) \\
Y_{i j} & =\left(\beta_{i j}+\Delta \beta_{i j}\right)\left(\bar{N}_{i j}+N_{i j}\right)-\beta_{i j} \bar{N}_{i j} \\
& =\beta_{i j} N_{i j}+\Delta \beta_{i j}\left(\bar{N}_{i j}+N_{i j}\right)
\end{aligned}
$$

また増加軸力 $N_{i j}$ は, 伸び剛性を $E A_{i j}$, 線膨張係数 をととすれば,

$$
\begin{aligned}
& N_{i j}=\frac{E A_{i j}}{l_{i j}}\left\{\alpha_{i j}\left(x_{i}-x_{j}\right)+\beta_{i j}\left(y_{i}-y_{j}\right)-\varepsilon t l_{i j}\right\} \\
& k_{i j}=\frac{\bar{N}_{i j}+N_{i j}}{E A_{i j}}, F_{i j}=\frac{E A_{i j}}{l_{i j}}
\end{aligned}
$$

とおいて, $X_{i j}, Y_{i j}$ を表わせば,

$$
\begin{aligned}
X_{i j}= & \alpha_{i j} N_{i j}+k_{i j} F_{i j} \beta^{2}{ }_{i j}\left(x_{i}-x_{j}\right) \\
& -k_{i j} F_{i j} \alpha_{i j} \beta_{i j}\left(\left(y_{i}-y_{j}\right)\right. \\
Y_{i j}= & \beta_{i j} N_{i j}-k_{i j} F_{i j} \alpha_{i j} \beta_{i j}\left(x_{i}-x_{i j}\right) \\
& +k_{i j} F_{i j} \alpha^{2}{ }_{i j}\left(y_{i}-y_{j}\right)
\end{aligned}
$$

となる。この式の第 2 項以下が, $-\beta_{i j} S_{i j}, \alpha_{i j} S_{i j}$ とな るものである。これに式 (1) を代入し， とおけば,

$$
a_{i j}=F_{i j} \alpha^{2}{ }_{i j}, \quad b_{i j}=F_{i j} \beta^{2}{ }_{i j}, \quad c_{i j}=F_{i j} \alpha_{i j} \beta_{i j}
$$

$$
\begin{aligned}
X_{i j}= & \left(a_{i j}+k_{i j} b_{i j}\right)\left(x_{i}-x_{j}\right) \\
& +c_{i j}\left(1-k_{i j}\right)\left(y_{i}-y_{j}\right)-E A_{i j} \alpha_{i j} \varepsilon t \\
Y_{i j}= & c_{i j}\left(1-k_{i j}\right)\left(x_{i}-x_{j}\right) \\
& +\left(b_{i j}+k_{i j} a_{i j}\right)\left(y_{i}-y_{j}\right)-E A_{i j} \beta_{i j} \varepsilon t
\end{aligned}
$$

を得る。これが, 軸力部材にお抢りる有限変形法の基本式 であり, $k_{i j}=0$ とすれば, 一般の微小変形理論による 変形法の式に一致することになる。

\section{（2）基礎方程式の誘導}

図のように, 主ケーブル節点を $i=0,1,2, \cdots, n$, 補剛 げた節点を $j=0,1,2, \cdots, m$ とする。式 (3)，(4)を 主ケーブルについて適用し，

$$
\begin{array}{lll}
\alpha_{i}=\alpha_{i, i-1}, & \beta_{i}=\beta_{i, i-1}, & a_{i}=a_{i, i-1} \\
b_{i}=b_{i, i-1}, & c_{i}=c_{i, i-1}, & k_{i}=k_{i, i-1}
\end{array}
$$

\section{図-2}

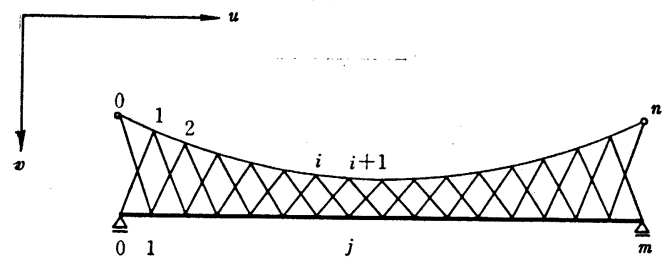

とおけば, $i$ 点のまわりの力のつりあいより，

$$
\begin{aligned}
& -\left(a_{i}+k_{i} b_{i}\right) x_{i-1}+\left(a_{i}+a_{i+1}+k_{i} b_{i}+k_{i+1} b_{i+1}\right. \\
& \left.\quad+\sum_{j} a_{i j}+\sum_{j} k_{i j} b_{i j}\right) x_{i}-\left(a_{i+1}+k_{i+1} b_{i+1}\right) x_{i+1} \\
& -c_{i}\left(1-k_{i}\right) y_{i-1}+\left\{c_{i}+c_{i+1}-k_{i} c_{i}-k_{i+1} c_{i+1}\right. \\
& \left.\quad+\sum_{j} c_{i j}\left(1-k_{i j}\right)\right\} y_{i}-c_{i+1}\left(1-k_{i+1}\right) y_{i+1} \\
& \quad-\sum_{j} c_{i j}\left(1-k_{i j}\right) y_{j}{ }^{\prime}-\sum_{j}\left(a_{i j}+k_{i j} b_{i j}\right) x_{j}{ }^{\prime}=U_{t i} \\
& \cdots \cdots \cdots \cdots \cdots(5) \\
& -c_{i}\left(1-k_{i}\right) x_{i-1}+\left\{c_{i}+c_{i+1}-k_{i} c_{i}-k_{i+1} c_{i+1}\right. \\
& \left.\quad+\sum_{j} c_{i j}\left(1-k_{i j}\right)\right\} x_{i}-c_{i+1}\left(1+k_{i+1}\right) x_{i+1} \\
& -\left(b_{i}+k_{i} a_{i}\right) y_{i-1}+\left(b_{i}+b_{i+1}+k_{i} a_{i}+k_{i+1} a_{i+1}\right. \\
& \left.\quad+\sum_{j} b_{i j}+\sum_{j} k_{i j} a_{i j}\right) y_{i}-\left(b_{i+1}+k_{i+1} a_{i+1}\right) y_{i+1} \\
& -\sum_{j}\left(b_{i j}+k_{i j} a_{i j}\right) y_{j}{ }^{\prime}-\sum_{j} c_{i j}\left(1-k_{i j}\right) x_{j}{ }^{\prime}=V_{t i}
\end{aligned}
$$

ただし, $x_{j}{ }^{\prime}, y_{j}{ }^{\prime}$ は補剛げた $j$ 点の変位,

$$
\begin{aligned}
& U_{t i}=E \varepsilon t\left(A_{i} \alpha_{i}-A_{i+1} \alpha_{i+1}\right)+E \varepsilon t \sum_{j} A_{i j} \alpha_{i j} \\
& V_{t i}=E \varepsilon t\left(A_{i} \beta_{i}-A_{i+1} \beta_{i+1}\right)+E \varepsilon t \sum_{j} A_{i j} \beta_{i j}
\end{aligned}
$$

つぎに, 補剛げた節点に集まる吊材張力の合力を $X_{j}$, $Y_{j}$ とすれば,

$$
\begin{aligned}
& -\sum_{i} c_{j i}\left(1-k_{j i}\right) x_{i}-\sum_{i}\left(b_{j i}+k_{j i} a_{j i}\right) y_{i} \\
& +y_{j}{ }_{i}\left(b_{j i}+k_{j i} a_{j i}\right)+x_{j}{ }^{\prime} \sum_{i} c_{j i}\left(1-k_{j i}\right) \\
& =V_{t j}{ }^{\prime}+Y_{j} \\
& -\sum_{i}\left(a_{j i}+k_{j i} b_{j i}\right) x_{i}-\sum_{i} c_{j i}\left(1-k_{j i}\right) y_{i} \\
& +y_{j}^{\prime} \sum_{i} c_{j i}\left(1-k_{j i}\right)+x_{j}^{\prime} \sum_{i}\left(a_{j i}+k_{j i} b_{j i}\right) \\
& =U_{t j}{ }^{\prime}+X_{j} \\
& V_{t j}{ }^{\prime}=E \varepsilon t \sum_{i} A_{j i} \beta_{j i}, \quad U_{t j}{ }^{\prime}=E \varepsilon t \sum_{i} A_{j i} \alpha_{j i}
\end{aligned}
$$

また, 補剛げたに㧍ける荷重と変位との関係は, 垂直 方向に対しては,

\section{図-3}

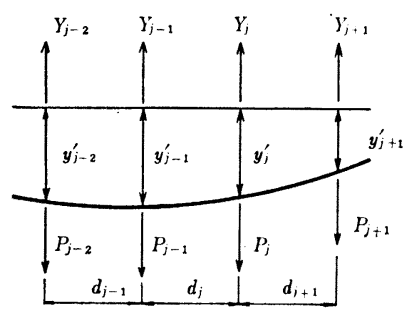

$$
\begin{array}{r}
-r_{j} M_{j-1}+\left(r_{j}+r_{j+1}\right) M_{j}-r_{j+1} M_{j+1}=P_{j}-Y_{j} \\
\cdots \cdots \cdots \cdots(9) \\
-r_{j} y^{\prime}{ }_{j-1}+\left(r_{j}+r_{j+1}\right) y_{j}{ }^{\prime}-\gamma_{j+1} y^{\prime}{ }_{j+1} \\
\quad=t_{j} M_{j-1}+2\left(t_{j}+t_{j+1}\right) M_{j}+t_{j+1} M_{j+1} \cdots(10)
\end{array}
$$

が成立する。ただし

$$
r_{j}=\frac{1}{d_{j}}, \quad t_{j}=\frac{d_{j}}{6 E I_{j}}
$$

$E I_{j}$ は, 補剛げた $j-1 \sim j$ 区間の曲げ剛性

$$
\text { ここで, }
$$




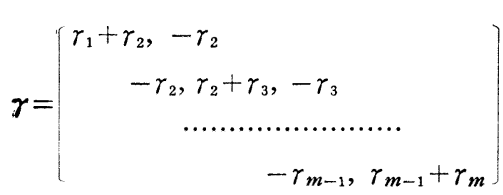

$$
\begin{aligned}
& \boldsymbol{t}=\left(\begin{array}{c}
2\left(t_{1}+t_{2}\right), t_{2} \\
t_{2}, 2\left(t_{2}+t_{3}\right), t_{3} \\
\ldots \ldots \ldots \ldots \ldots \ldots \ldots \ldots \ldots \ldots \ldots \ldots \ldots \ldots \\
t_{m-1}, 2\left(t_{m-1}+t_{m}\right)
\end{array}\right)
\end{aligned}
$$

そおいて行列で表わせば

$$
\boldsymbol{r} \boldsymbol{M}=\boldsymbol{P}-\boldsymbol{Y}, \quad \boldsymbol{r} \boldsymbol{y}^{\prime}=\boldsymbol{t} \boldsymbol{M}
$$

したがって, $h=\gamma t^{-1} \gamma$ とおけば

$$
\boldsymbol{Y}=\boldsymbol{P}-\boldsymbol{h} \boldsymbol{y}^{\prime}
$$

を得る。水平方向に対しては,

$$
\begin{array}{r}
-F_{j}{ }^{\prime} x^{\prime}{ }_{j-1}+\left(F_{j}{ }^{\prime}+F^{\prime}{ }_{j+1}\right) x_{j}{ }^{\prime}-F^{\prime}{ }_{j+1} x^{\prime}{ }_{j+1} \\
=-X_{j}+U_{t j}{ }^{\prime \prime} \ldots \ldots \ldots \ldots \ldots \ldots \ldots \ldots \ldots \ldots \ldots \ldots \ldots \ldots \ldots \ldots \ldots \ldots \ldots \ldots \ldots \ldots \ldots \ldots
\end{array}
$$

ただし，

$$
F_{j}{ }^{\prime}=\frac{E A_{j^{\prime}}}{d_{j}}, \quad U_{t j^{\prime \prime}}=E \varepsilon t\left(A_{j^{\prime}}-A^{\prime}{ }_{j+1}\right)
$$

$E A_{j}{ }^{\prime}$ : 補剛げた $j-1 \sim j$ 区間の伸び剛性 $j=0,1,2, \cdots, m$ として行列で表わせば,

$\boldsymbol{F} \boldsymbol{x}^{\prime}=-\boldsymbol{X}+\boldsymbol{U}_{t}^{\prime \prime}$

ただし，

$$
\boldsymbol{F}=\mid \begin{array}{r}
F_{1}{ }^{\prime},-F_{1}{ }^{\prime} \\
-F_{1}{ }^{\prime}, F_{1}{ }^{\prime}+F_{2}{ }^{\prime},-F_{2}{ }^{\prime} \\
-F_{2}{ }^{\prime}, F_{2}{ }^{\prime}+F_{3}{ }^{\prime},-F_{3}{ }^{\prime} \\
\ldots \ldots \ldots \ldots \ldots \ldots \ldots \ldots . . . \cdots \cdots \cdots \\
\quad-F_{m}{ }^{\prime}, F_{m}{ }^{\prime}
\end{array}
$$

さらに, 式 (5)，(6)，(7)，(8) についてもつぎ のように行列を用いて表示する。

$$
\begin{aligned}
& (\boldsymbol{a}+\overline{\boldsymbol{a}}) \boldsymbol{x}+(\boldsymbol{c}+\overline{\boldsymbol{c}}) \boldsymbol{y}-\boldsymbol{c}^{\prime} \boldsymbol{y}^{\prime}-\boldsymbol{a}^{\prime} \boldsymbol{x}^{\prime}=\boldsymbol{U}_{t} \\
& (\boldsymbol{c}+\overline{\boldsymbol{c}}) \boldsymbol{x}+(\boldsymbol{b}+\overline{\boldsymbol{b}}) \boldsymbol{y}-\boldsymbol{b}^{\prime} \boldsymbol{y}^{\prime}-\boldsymbol{c}_{1}{ }^{\prime} \boldsymbol{x}^{\prime}=V_{t} \\
& -\boldsymbol{c}^{*} \boldsymbol{x}-\boldsymbol{b}^{\prime *} \boldsymbol{y}+\tilde{\boldsymbol{b}} \boldsymbol{y}^{\prime}+\tilde{\boldsymbol{c}} \boldsymbol{x}^{\prime}=\boldsymbol{V}_{t}{ }^{\prime}+\boldsymbol{Y} \cdots \\
& -\boldsymbol{a}^{\prime *} \boldsymbol{x}-\boldsymbol{c}_{1}{ }^{*} \boldsymbol{y}+\tilde{\boldsymbol{c}}{ }^{*} \boldsymbol{y}^{\prime}+\tilde{\boldsymbol{a}} \boldsymbol{x}^{\prime}=\boldsymbol{U}_{t}+\boldsymbol{X}
\end{aligned}
$$
ただし，

$$
\begin{aligned}
& \boldsymbol{x}=\left(\begin{array}{l}
x_{1} \\
x_{2} \\
\cdots \\
x_{n-1}
\end{array}\right), \quad \boldsymbol{y}=\left(\begin{array}{l}
y_{1} \\
y_{2} \\
\cdots \\
y_{n-1}
\end{array}\right), \boldsymbol{y}^{\prime}=\left(\begin{array}{l}
y_{1}^{\prime} \\
y_{2}^{\prime} \\
\cdots \\
y_{m-1}^{\prime}
\end{array}\right), \boldsymbol{x}^{\prime}=\left(\begin{array}{l}
x_{0}{ }^{\prime} \\
x_{1}{ }^{\prime} \\
\cdots \\
x_{m}{ }^{\prime}
\end{array}\right) \\
& \boldsymbol{a}=\left(\begin{array}{c}
a_{1}+a_{2}+k_{1} b_{1}+k_{2} b_{2},-a_{2}-k_{2} b_{2} \\
-a_{2}-k_{2} b_{2}, a_{2}+a_{3}+k_{2} b_{2}+k_{3} b_{3},-a_{3}-k_{3} b_{3} \\
\ldots \ldots \ldots \ldots \ldots \ldots \ldots \ldots \ldots \ldots \ldots \ldots \ldots \ldots \\
-a_{n-1}-k_{n-1} b_{n-1}, a_{n-1}+a_{n}+k_{n-1} b_{n-1} \\
+k_{n} b_{n}
\end{array}\right)
\end{aligned}
$$

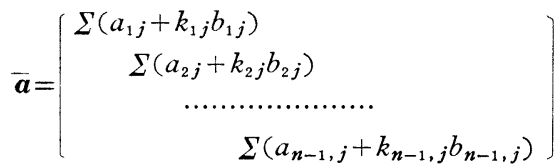

$$
\begin{aligned}
& \overline{\boldsymbol{c}}=\left(\begin{array}{c}
\sum c_{1 j}\left(1-k_{1 j}\right) \\
\sum c_{2 j}\left(1-k_{2 j}\right) \\
\ldots \ldots \ldots \ldots \ldots \ldots \ldots \ldots \ldots \ldots \ldots \ldots \\
\sum c_{n-1, j}\left(1-k_{n-1, j}\right)
\end{array}\right)
\end{aligned}
$$

$$
\begin{aligned}
& \tilde{\boldsymbol{a}}=\left[\begin{array}{c}
\Sigma\left(a_{0 i}+k_{0 i} b_{0 i}\right) \\
\Sigma\left(a_{1 i}+k_{1 i} b_{1 i}\right) \\
\ldots \ldots \ldots \ldots \ldots \ldots \ldots \\
\Sigma\left(a_{m i}+k_{m i} b_{m i}\right)
\end{array}\right] \\
& \tilde{\boldsymbol{b}}=\left(\begin{array}{c}
\Sigma\left(b_{1 i}+k_{1 i} a_{1 i}\right) \\
\Sigma\left(b_{2 i}+k_{2 i} a_{2 i}\right) \\
\ldots \ldots \ldots \ldots \ldots \ldots \ldots \ldots \ldots \\
\Sigma\left(b_{m-1, i}+k_{m-1, i} a_{m-1, i}\right)
\end{array}\right) \\
& \tilde{\boldsymbol{c}}=\left[\begin{array}{c}
0, \sum c_{1 i}\left(1-k_{1 i}\right) \\
\sum c_{2 i}\left(1-k_{2 i}\right) \\
\ldots \ldots \ldots \ldots \ldots \ldots \ldots \ldots \ldots \ldots \\
\sum c_{m-1, i}\left(1-k_{m-1, i}\right), 0
\end{array}\right]
\end{aligned}
$$

$\boldsymbol{b}, \overline{\boldsymbol{b}}$ は, $\boldsymbol{a}, \overline{\boldsymbol{a}}$ において $a$ と $b$ を入れかえたもの， $\boldsymbol{b}^{\prime}, \boldsymbol{c}^{\prime}$ はその $i j$ 要素がそれぞれ $b_{i j}+k_{i j} a_{i j}, c_{i j}\left(1-k_{i j}\right)$ とな る $n-1$ 行 $m-1$ 列の行列, $\boldsymbol{a}^{\prime}, \boldsymbol{c}_{1}{ }^{\prime}$ は, その $i j$ 要素が それぞれ $a_{i, j-1}+k_{i, j-1} b_{i, j-1}, c_{i, j-1}\left(1-k_{i, j-1}\right)$ となる $n-1$ 行 $m+1$ 列の行列, $\boldsymbol{a}^{\prime * な と ゙ は ~} \boldsymbol{a}^{\prime}$ の転置行列である。

式 $(7)^{\prime},(8)^{\prime}$ に (11), (12)' を代入して, $\boldsymbol{X}, \boldsymbol{Y}$ を消去して整理すれば,

$$
\left(\begin{array}{cccc}
\boldsymbol{a}+\overline{\boldsymbol{a}} & \boldsymbol{c}+\overline{\boldsymbol{c}} & -\boldsymbol{c}^{\prime} & -\boldsymbol{a}^{\prime} \\
\boldsymbol{c}+\overline{\boldsymbol{c}} & \boldsymbol{b}+\overline{\boldsymbol{b}} & -\boldsymbol{b}^{\prime} & -\boldsymbol{c}_{1}{ }^{\prime} \\
-\boldsymbol{c}^{\prime *} & -\boldsymbol{b}^{\prime *} & \tilde{\boldsymbol{b}}+\boldsymbol{h} & \tilde{\boldsymbol{c}} \\
-\boldsymbol{a}^{\prime *} & -\boldsymbol{c}_{1}{ }^{*} & \tilde{\boldsymbol{c}}^{*} & \tilde{\boldsymbol{a}}+\boldsymbol{F}
\end{array}\right)\left(\begin{array}{l}
\boldsymbol{x} \\
\boldsymbol{y} \\
\boldsymbol{y}^{\prime} \\
\boldsymbol{x}^{\prime}
\end{array}\right)=\left(\begin{array}{c}
\boldsymbol{U} \\
\boldsymbol{V} \\
\boldsymbol{V}^{\prime} \\
\boldsymbol{U}^{\prime}
\end{array}\right)
$$

ただし

$$
\boldsymbol{V}^{\prime}=\boldsymbol{P}+\boldsymbol{V}_{t}, \quad \boldsymbol{U}^{\prime}=\boldsymbol{U}_{t}^{\prime}+\boldsymbol{U}_{t}^{\prime \prime}
$$

ここで， $\tilde{\boldsymbol{a}}+\boldsymbol{F}$ は， $\boldsymbol{t}$ などと同じく対角要素とその両 側の要素のみのいわゆる tri-diagonal matrix であるの で, その逆行列は, 後述のように簡単に求めることがで きる。このことを利用して $\boldsymbol{x}^{\prime}$ を消去し, 式 (13) の元 数を引下げることにする。

すなわち, $\boldsymbol{D}=(\tilde{\boldsymbol{a}}+\boldsymbol{F})^{-1}$ とおいて式 (13) を変形す れば,

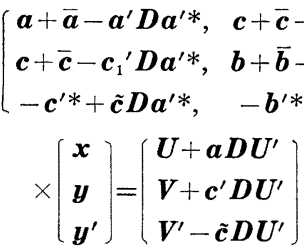

$$
\begin{aligned}
& \boldsymbol{x}^{\prime}=\boldsymbol{D} \boldsymbol{a}^{\prime *} \boldsymbol{x}+\boldsymbol{D} \boldsymbol{c}_{1}{ }^{*} \boldsymbol{y}-\boldsymbol{D} \tilde{c}^{*} \boldsymbol{y}^{\prime}+\boldsymbol{D} \boldsymbol{U}^{\prime}
\end{aligned}
$$

式 (14), (15) が, 任意形式の吊橋の変位に関する基 礎方程式である。

\section{(3) 各形式への適用}

式（14）をつぎのように略記する。

$$
\left(\begin{array}{lll}
\boldsymbol{A} & \boldsymbol{C} & \boldsymbol{C}^{\prime} \\
\boldsymbol{C}^{*} & \boldsymbol{B} & \bar{B} \\
\boldsymbol{C}^{\prime *} & \overline{B^{*}} & \boldsymbol{B}^{\prime}
\end{array}\right)\left(\begin{array}{l}
\boldsymbol{x} \\
y \\
y^{\prime}
\end{array}\right)=\left(\begin{array}{l}
u \\
\boldsymbol{v} \\
\boldsymbol{v}^{\prime}
\end{array}\right)
$$

補剛げた， $j$ 節点がヒンジの場合には， $\boldsymbol{h}$ の計算にお いて $\boldsymbol{t}$ の $j j$ 要素を 1 , 他の $j$ 行と $j$ 列の要素をすべ て 0 として逆行列を求め, その $j$ 列要素を 0 とおきこれ を $t^{-1}$ とする。 


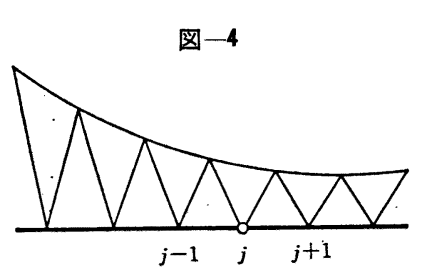

図一5

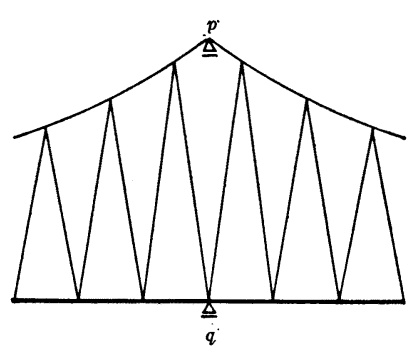

また塔頂の主ケーブル節点を $p$, 補剛げたの中間支点 を $q$ で代表させ,

$i=n-1$ 次の単位行列の第 $p$ 行を 0 としたもの $\boldsymbol{j}=m-1$ 次の単位行列の第 $q$ 行を 0 としたもの $i^{\prime}, j^{\prime}: i, j$ の補数行列

とすれば, 塔頂, 中間支点の条件を加味した基礎方程式 は,

$$
\left(\begin{array}{ccc}
A & C i & C^{\prime} J \\
i C^{*} & i^{\prime}+i B i & i B j \\
j C^{\prime *} & j B * i & j^{\prime}+j B^{\prime} j
\end{array}\right)\left(\begin{array}{l}
x \\
y \\
y^{\prime}
\end{array}\right)=\left(\begin{array}{l}
u \\
i v \\
j v^{\prime}
\end{array}\right)
$$

となる。

図のように補剛げたが中間支点で不連続な場合には， $q-1, q$ に支点条件とヒンジの条件を入れ, $A_{q^{\prime}}{ }^{\prime}=0$ とし て, $q-1 \sim q$ 区間の伸び剛度を 0 にしてやればよい。

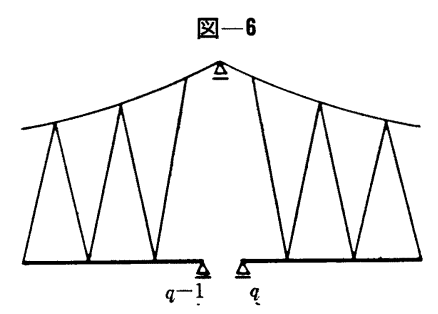

こうして, 各節点の変位が求まれば, ケーブル張力, けたの曲げモーメントなどは, 前述の式で簡単に求ま る。

また補剛げたのたわみ角 $\theta_{\boldsymbol{j}}$ を求めるには,

$$
K_{j}=\frac{2 E I_{j}}{d_{j}}, K_{j}{ }^{\prime}=\frac{6 E I_{j}}{d_{j}{ }^{2}}
$$

として,

$$
\left(\begin{array}{c}
\theta_{0} \\
\theta_{1} \\
\theta_{2} \\
\cdots \\
\theta_{m}
\end{array}\right)=\left[\begin{array}{c}
2 K_{1}, K_{1} \\
K_{1}, 2\left(K_{1}+K_{2}\right), K_{2} \\
K_{2}, 2\left(K_{2}+K_{3}\right), K_{3} \\
\cdots \cdots \cdots \cdots \cdots \cdots \cdots \cdots \cdots \cdots \\
K_{m}, 2 K_{m}
\end{array}\right)^{-1}
$$

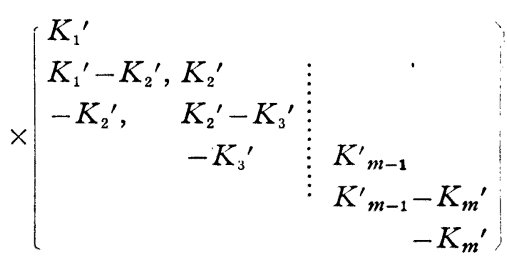$$
\times\left(\begin{array}{c}
y_{1} \\
y_{2} \\
\vdots \\
y_{m-1}
\end{array}\right)
$$

より求めればよい。

\section{（4）微分方程式 (Melan) との関連}

いま, 主ケーブル, 補剛げたの断面は一様, 吊材は垂 直方向のみとし, 吊材の伸びを無視すれば, 式 (13) は つぎのように簡単になる。

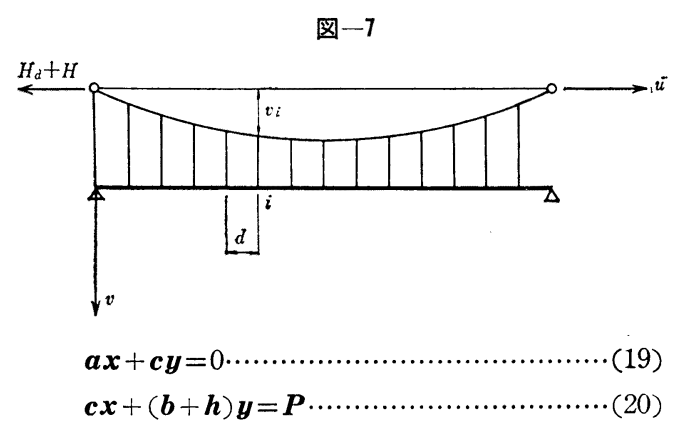

$\boldsymbol{a}, \boldsymbol{b}, \boldsymbol{c}$ を $k$ を含む部分とそうでない部分の二つの行 列にわける。たとえば

$$
\boldsymbol{a}=\left(\begin{array}{r}
a_{1}+a_{2},-a_{2} \\
-a_{2}, a_{2}+a_{3},-a_{3} \\
\ldots \ldots \ldots \ldots \ldots \ldots \ldots \\
-a_{n-1}, a_{n-1}+a_{n}
\end{array}\right)
$$

$$
\boldsymbol{k}_{b}=\left(\begin{array}{c}
k_{1} b_{1}+k_{2} b_{2},-k_{2} b_{2} \\
-k_{2} b_{2}, k_{2} b_{2}+k_{3} b_{3},-k_{3} b_{3} \\
\ldots \ldots \ldots \ldots \ldots \ldots \ldots \ldots \ldots \ldots \ldots \ldots \ldots \ldots \ldots \ldots \ldots \ldots \ldots \ldots \ldots \\
-k_{n-1} b_{n-1}, k_{n-1} b_{n-1}+k_{n} b_{n}
\end{array}\right)
$$

とおけば

$$
\begin{aligned}
& \left(\boldsymbol{a}+\boldsymbol{k}_{b}\right) \boldsymbol{x}+\left(\boldsymbol{c}-\boldsymbol{k}_{c}\right) \boldsymbol{y}=0 \\
& \left(\boldsymbol{c}-\boldsymbol{k}_{\boldsymbol{i}}\right) \boldsymbol{x}+\left(\boldsymbol{b}+\boldsymbol{k}_{\boldsymbol{a}}+\boldsymbol{h}\right) \boldsymbol{y}=\boldsymbol{P}
\end{aligned}
$$

式 (21) を変形して

$$
(\boldsymbol{c} \boldsymbol{x}+\boldsymbol{b} \boldsymbol{y})+\left(-\boldsymbol{k}_{c} \boldsymbol{x}+\boldsymbol{k}_{a} \boldsymbol{y}\right)+\boldsymbol{\gamma} \boldsymbol{M}=\boldsymbol{P}
$$

第 1 項の $i$ 行要素は

$$
\begin{aligned}
(\boldsymbol{c} \boldsymbol{x}+\boldsymbol{b} \boldsymbol{y})_{i}= & -c_{i} x_{i-1}+\left(c_{i}+c_{i+1}\right) x_{i}-c_{i+1} x_{i+1} \\
& -b_{i} y_{i-1}+\left(b_{i}+b_{i+1}\right) y_{i}-b_{i+1} y_{i+1} \\
= & \beta_{i} N_{i}-\beta_{i+1} N_{i+1}=-\frac{v_{i-1}-2 v_{i}+v_{i+1}}{d} H
\end{aligned}
$$

また第 2 項は，

$$
\begin{aligned}
\left(-\boldsymbol{k}_{c} \boldsymbol{x}+\boldsymbol{k}_{a}\right)_{i}= & k_{i} c_{i} x_{i-1}-\left(k_{i} c_{i}+k_{i+1} c_{i+1}\right) x_{i} \\
& +k_{i+1} c_{i+1} x_{i+1}-k_{i} a_{i} y_{i-1} \\
& +\left(k_{i} a_{i}+k_{i+1} a_{i+1}\right) y_{i}-k_{i+1} a_{i+1} y_{i+\mathbf{1}}
\end{aligned}
$$

しかるに， 


$$
\begin{aligned}
& k_{i} c_{i}=\frac{H+H_{d}}{E_{c} A_{c}} \frac{1}{\alpha_{i}} \frac{E_{c} A_{c}}{l_{i}} \alpha_{i} \beta_{i}=\frac{H_{d}+H}{d} \alpha_{i} \beta_{i} \\
& k_{i} a_{i}=\frac{H+H_{d}}{E_{c} A_{c}} \frac{1}{\alpha_{i}} \frac{E_{c} A_{c}}{l_{i}} \alpha_{i}{ }^{2}=\frac{H_{d}+H}{d} \alpha_{i}{ }^{2}
\end{aligned}
$$

したがって，

$$
\begin{aligned}
\left(-\boldsymbol{k}_{c} \boldsymbol{x}+\boldsymbol{k}_{a} \boldsymbol{y}\right)_{i} \\
=\frac{H_{d}+H}{d}\left\{\alpha_{i} \beta_{i} x_{i-1}-\left(\alpha_{i} \beta_{i}+\alpha_{i+1} \beta_{i+1}\right) x_{i}\right. \\
\quad+\alpha_{i+1} \beta_{i+1} x_{i+1}-\alpha_{i}{ }^{2} y_{i-1} \\
\left.\quad+\left(\alpha_{i}{ }^{2}+\alpha^{2}{ }_{i+1}\right) y_{i}-\alpha^{2}{ }_{i+1} y_{i+1}\right\}
\end{aligned}
$$

一方, 式 (19) の $i$ 行は $\boldsymbol{k}_{b}, \boldsymbol{k}_{c}$ を省略して

$$
\begin{gathered}
-\frac{\alpha_{i}^{2}}{l_{i}} x_{i-1}+\left(\frac{\alpha_{i}{ }^{2}}{l_{i}}+\frac{\alpha^{2}{ }_{i+1}}{l_{i+1}}\right) x_{i}-\frac{\alpha^{2}{ }_{i+1}}{l_{i+1}} x_{i+1} \\
-\frac{\alpha_{i} \beta_{i}}{l_{i}} y_{i-1}+\left(\frac{\alpha_{i} \beta_{i}}{l_{i}}+\frac{\alpha_{i+1} \beta_{i+1}}{l_{i+1}}\right) y_{i} \\
-\frac{\alpha_{i+1} \beta_{i+1}}{l_{i+1}} y_{i+1}=0 \\
\alpha_{i} \doteqdot \alpha_{i+1}, \quad \beta_{i} \div \beta_{i+1}, \quad l_{i} \doteqdot l_{i+1} \text { であるので, } \\
-\alpha_{i} \beta_{i} x_{i-1}+\left(\alpha_{i} \beta_{i}+\alpha_{i+1} \beta_{i+1}\right) x_{i}-\alpha_{i+1} \beta_{i+1} x_{i+1} \\
-\beta_{i}{ }^{2} y_{i-1}+\left(\beta_{i}{ }^{2}+\beta^{2}{ }_{i+1}\right) y_{i}-\beta^{2}{ }_{i+1} y_{i+1}=0
\end{gathered}
$$

これを式 (24) に代入して $x$ の項を消去すれば，

$$
\left(-\boldsymbol{k}_{c} \boldsymbol{x}+\boldsymbol{K}_{a} \boldsymbol{y}\right)_{i}=\frac{-y_{i-1}+2 y_{i}-y_{i+1}}{d}\left(H_{d}+H\right)
$$

式 (23), (24), (25) より

$$
\begin{gathered}
-\frac{M_{i-1}-2 M_{i}+M_{i+1}}{d^{2}}-\frac{v_{i-1}-2 v_{i}+v_{i+1}}{d^{2}} H \\
-\frac{y_{i-1}-2 y_{i}+y_{i+1}}{d^{2}}\left(H_{d}+H\right)=\frac{P_{i}}{d} \cdots(26)
\end{gathered}
$$

すなわち,

$$
-\frac{\Delta^{2} M}{\Delta u^{2}}-H \frac{\Delta^{2} v}{\Delta u^{2}}-\left(H_{d}+H\right) \frac{\Delta^{2} y}{\Delta u^{2}}=\frac{P_{i}}{d}
$$

微分方程式に直せば,

$$
E I \frac{d^{4} y}{d u^{4}}-H \frac{d^{2} v}{d u^{2}}-\left(H_{d}+H\right) \frac{d^{2} y}{d u^{2}}=p \cdots
$$

となり Melan の基礎微分方程式が得られる。

\section{(5) 補遇}

式（17）を解くためには，主ケーブルにおける $k_{i}$, 吊 材における $k_{i j}$ を仮定しなければならない。これらをす べて0としてしまえば，弾性理論ということになる。

$$
k_{i}=\frac{\bar{N}_{i}+N_{i}}{E_{c} A_{c}}, \quad k_{i j}=\frac{\bar{N}_{i j}+N_{i j}}{E_{c}^{\prime} A_{i j}}
$$

ふつう， $\bar{N}_{i}, \bar{N}_{i j}$ 浪死荷重などによるもので, 既知 であり, $N_{i}, N_{i j}$ を省略して $k_{i}, k_{i j}$ を決めてしまえ ば, 線型化された暁度理論に対応する。

とくに厳密解を要求しない場合には, 吊材の $k_{i j}$ をす べて 0 とおき,

$$
k^{\prime}=\frac{H_{d}}{E_{c} A_{c}}
$$

を定め,

$$
k_{i}=\frac{k^{\prime}}{\alpha_{i}}
$$

として計算を進めたとしても, 既住の解法にくらべれ ば,より厳密解に近い值が得られる。

式（17）は，あらゆる形式を包含するものであるが， とくに垂直吊材のみで，主ケーブル節点と補剛げたの節 点が 1 対 1 の対応となる場合を考えてみよう。吊材の伸 びを無視し，補剛げたの伸縮はないものとすれば，式 (13) は,

$$
\left(\begin{array}{lll}
\boldsymbol{a}+\boldsymbol{K}, & \boldsymbol{c}, & -\boldsymbol{x} \\
\boldsymbol{c}, & \boldsymbol{b}+\boldsymbol{h}, & \\
-\boldsymbol{\kappa}^{*} & & \sum \kappa
\end{array}\right]\left[\begin{array}{l}
\boldsymbol{x} \\
\boldsymbol{y} \\
x^{\prime}
\end{array}\right)=\left[\begin{array}{l}
\boldsymbol{U}_{t} \\
\boldsymbol{V}_{t}+\boldsymbol{P} \\
0
\end{array}\right]
$$

ここで,

$\kappa_{i}=\frac{\bar{N}_{i i}+N_{i i}}{l_{i i}}:$ 吊材張力を吊材長で割ったもの

$$
\boldsymbol{K}: \kappa_{i}(i=1,2, \cdots, n-1) \text { による対角行列 }
$$

$\boldsymbol{\kappa}, \boldsymbol{\kappa}^{*}: \kappa_{i}(i=1,2, \cdots, n-1)$ による列および行べク トル

$x^{\prime}$ を消去すれば，

$$
\begin{aligned}
& \left(\boldsymbol{a}+\boldsymbol{K}-\mu \boldsymbol{\kappa} \boldsymbol{x}^{*}\right) \boldsymbol{x}+\boldsymbol{c y}=U_{t} \\
& \boldsymbol{c x}+(\boldsymbol{b}+\boldsymbol{h}) \boldsymbol{y}=V_{t}+\boldsymbol{P} \ldots \ldots .
\end{aligned}
$$

ただし，

$$
\mu=\frac{1}{\sum \kappa}
$$

このとき, 補剛げたの水平移動量 $x^{\prime}$ は,

$$
x^{\prime}=\mu \boldsymbol{\kappa} * \boldsymbol{x}=\frac{\kappa_{1} x_{1}+\kappa_{2} x_{2}+\cdots \kappa_{n-1} x_{n-1}}{\sum \kappa}
$$

となり，主ケーブル節点変位の吊材の影響を考えた平均 值となっている。

$$
\left(\boldsymbol{a}+\boldsymbol{K}-\mu \boldsymbol{\kappa} \boldsymbol{\kappa}^{*}\right)^{-1}=\mathfrak{A}
$$

とおいて $\boldsymbol{x}$ を消去すると

$$
(b+h-c \mathfrak{A} c) y=V_{t}+P-c \mathfrak{A} U_{t}
$$

補剛げた曲げモーメントに関する方程式に直せば,

$$
\{(b-c \mathfrak{A} c) m t+\gamma\} M=V_{t}+P-c \mathfrak{X} U_{t}
$$

となる。ここで $\boldsymbol{m}$ は, 補剛げたを単純ばりとしたとき の曲げモーメント影響線行列であり，rの逆行列でむあ る。

つぎに, 以下のような諸元の垂直吊材吊橋を例にとり $k^{\prime}=\left(H_{d}+H\right) / E_{c} A_{c}$ の変動による影響を調べてみるこ とにする。

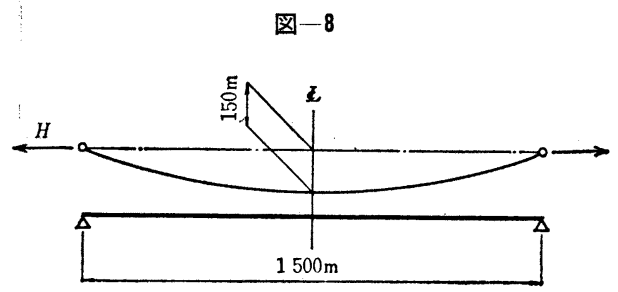

主ケーブル死荷重張力 $H_{d}=29494 \mathrm{t}$ 補剛トラス換算断面二次モーメント $I=2.04 \mathrm{~m}^{4}$ 主ケーブル断面積 $\quad A_{c}=0.8017 \mathrm{~m}^{2}$ 主ケーブル弾性係数 $\quad E_{c}=20 \times 10^{6} \mathrm{t} / \mathrm{m}^{2}$ 
この場合の $k^{\prime}$ は，大体，つぎのようになる。

$$
k^{\prime} \div \frac{H_{d}}{E_{c} A_{c}}=0.0018
$$

いま, $H_{d}+H=0 \sim 35000 \mathrm{t}$ まで 8 段階に変化させた ときの単位格点荷重 (支間を 24 等分) による最大曲げ モーメント図, その他を図示するとつぎのようになる。

図一9＼cjkstart最大および最小曲げモーメン図

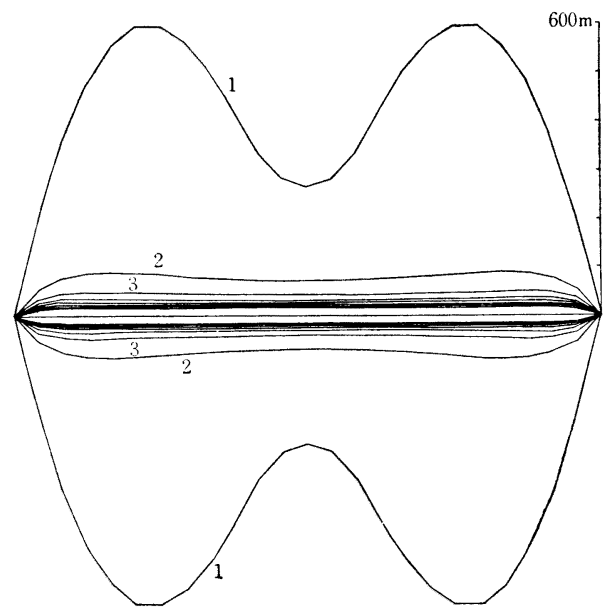

図一10 吊材張力影響線 (1/4 点)

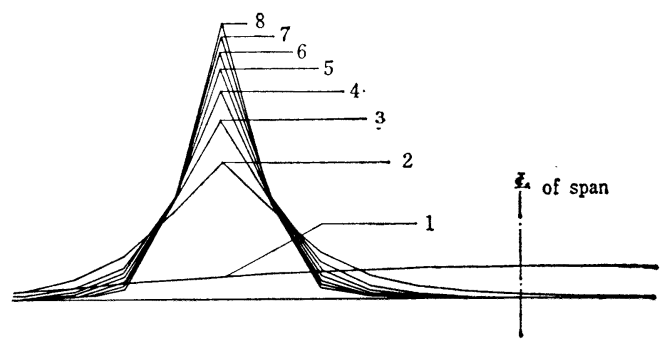

図一11曲げモーメント影響線

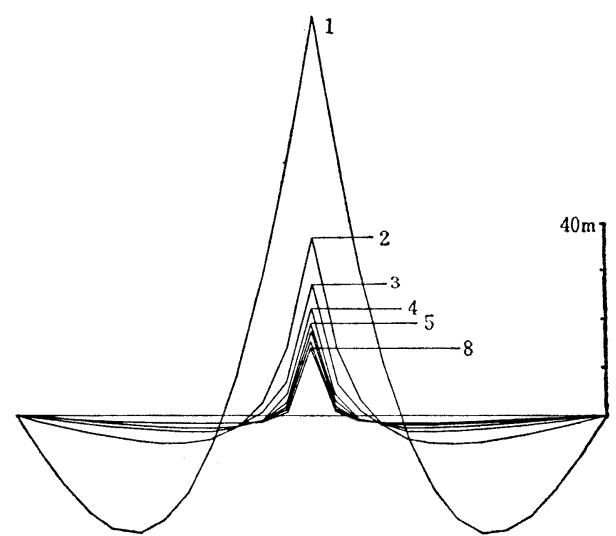

\begin{tabular}{r|r|r||c|c|c}
\hline & \multicolumn{1}{|c|}{$H$} & \multicolumn{1}{|c|}{$k^{\prime}$} & & $H$ & $k^{\prime}$ \\
\hline 1 & 0 & 0 & 5 & 20000 & 0.00125 \\
2 & 5000 & 0.00031 & 6 & 25000 & 0.00156 \\
3 & 10000 & 0.00063 & 7 & 30000 & 0.00188 \\
4 & 15000 & 0.00094 & 8 & 35000 & 0.00219 \\
\hline
\end{tabular}

\section{3. 横荷重を受ける吊橋}

\section{（1）基本式の誘導}

横荷重の場合の吊橋の変形は, 面外変形のみとし, 主 ケーブル，および吊材の伸縮は考えないものとする。

このような部材の材端面外力は, 前章 図一1の $S_{i j}$ に相当するものとして, 次式で与えられる。

$$
S_{i j}=\left(y_{i}-y_{j}\right) \frac{\bar{N}_{i j}+N_{i j}}{l_{i j}}
$$

主ケーブル $i^{\prime}$ 点のまわりの面外力のつりあいより

$$
S_{i^{\prime} i-1^{\prime}}+S_{i^{\prime} i+1^{\prime}}+S_{i^{\prime} i}=P_{i}^{\prime}
$$

図-12
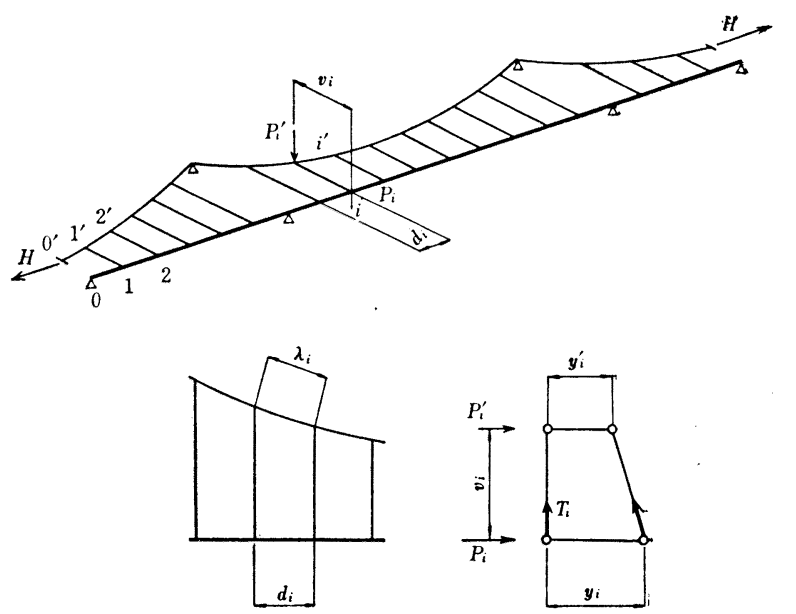

図-13

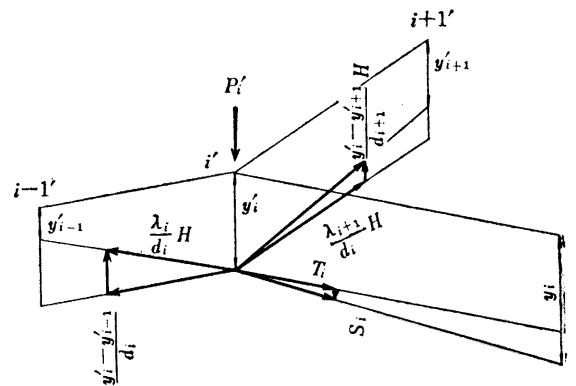

$$
\begin{aligned}
& \frac{\bar{N}_{i}}{l_{i}}\left(y_{i}{ }^{\prime}-y^{\prime}{ }_{i-1}\right)+\frac{\bar{N}_{i+1}}{l_{i+1}}\left(y_{i}{ }^{\prime}-y^{\prime}{ }_{i+1}\right) \\
& +\frac{T_{i}}{v_{i}}\left(y_{i}{ }^{\prime}-y_{i}\right)=P_{i}{ }^{\prime}
\end{aligned}
$$

すなわち

$$
\begin{aligned}
& H\left\{-\frac{1}{d_{i}} y^{\prime}{ }_{i-1}+\left(\frac{1}{d_{i}}+\frac{1}{d_{i+1}}\right) y_{i}{ }^{\prime}-\frac{1}{d_{i+1}} y_{i+1}^{\prime}\right\} \\
& +\frac{T_{i}}{v_{i}}\left(y_{i}^{\prime}-y_{i}\right)=P_{i}^{\prime}
\end{aligned}
$$

また，補剛げた節点については，

$$
-\frac{1}{d_{i}} M_{i-1}+\left(\frac{1}{d_{i}}+\frac{1}{d_{i+1}}\right) M_{i}-\frac{1}{d_{i+1}} M_{i+1}
$$




$$
\begin{aligned}
& \quad=P_{i}-\frac{T_{i}}{v_{i}}\left(y_{i}-y_{i}{ }^{\prime}\right) \ldots \ldots \ldots \ldots \ldots \ldots \ldots . . . \\
& -\frac{1}{d_{i}} y_{i-1}+\left(\frac{1}{d_{i}}+\frac{1}{d_{i+1}}\right) y_{i}-\frac{1}{d_{i+1}} y_{i+1} \\
& =t_{i} M_{i}+2\left(t_{i}+t_{i+1}\right) M_{i}+t_{i+1} M_{i+1} \cdots \cdots \cdots
\end{aligned}
$$

これらを行列で表わせば,

$$
\begin{aligned}
& H \boldsymbol{w} \boldsymbol{\gamma} \boldsymbol{y}^{\prime}+\boldsymbol{y}^{\prime}-\boldsymbol{y}^{\prime}=\boldsymbol{w} \boldsymbol{P}^{\prime} \\
& \boldsymbol{w} \boldsymbol{\gamma} \boldsymbol{M}=\boldsymbol{w} \boldsymbol{P}-\boldsymbol{y}+\boldsymbol{y}^{\prime} \\
& \boldsymbol{\gamma} \boldsymbol{y}=\boldsymbol{t} \boldsymbol{M}
\end{aligned}
$$

ここで,

$$
\boldsymbol{w}=\left(\begin{array}{ccc}
\frac{v_{1}}{T_{1}} & & \\
& \frac{v_{2}}{T_{2}} & \\
& \ldots \ldots \ldots \\
& & \frac{v_{n-1}}{T_{n-1}}
\end{array}\right]
$$

$\boldsymbol{y}, \boldsymbol{y}^{\prime}$ : 補剛げたおよび主ケーブルのたわみベクトル

$\boldsymbol{P}, \boldsymbol{P}^{\prime}$ : 補剛げたおよび主ケーブルの横荷重ベクトル

$$
\boldsymbol{M}: \text { 補剛げたの曲げモーメントベクトル }
$$

以上より $\boldsymbol{M}$ を消去すれば，主ケーブルおよび補剛げ たの節点の変位に関する連立方程式と等価のつぎの行列 方程式を得る。

$$
\left[\begin{array}{rr}
A & -I \\
-I & B
\end{array}\right]\left[\begin{array}{l}
y^{\prime} \\
y
\end{array}\right]=\left[\begin{array}{l}
w P^{\prime} \\
w P
\end{array}\right]
$$

ただし，

$$
\begin{aligned}
& \boldsymbol{I}: n-1 \text { 次の単位行列 } \\
& \boldsymbol{A}=\boldsymbol{I}+H \boldsymbol{w} \boldsymbol{\gamma} \\
& \boldsymbol{B}=\boldsymbol{I}+\boldsymbol{w} \boldsymbol{\gamma} \boldsymbol{t}^{-1} \boldsymbol{\gamma}
\end{aligned}
$$

中間支点がある場合, 中間支点の番号を $j, k, \cdots$ とし $\tau$,

$\boldsymbol{i}: \boldsymbol{I}$ の $j$ 行, $k$ 行, $\cdots$ を 0 とおいたもの

$\boldsymbol{i}^{\prime}: \boldsymbol{i}$ の補数行列 $I-i$

とすれば，式（38）はつぎのように変換される。

$$
\begin{aligned}
& \left(\left[\begin{array}{ll}
i^{\prime} & \\
& i^{\prime}
\end{array}\right]+\left[\begin{array}{r}
i \\
i
\end{array}\right]\left[\begin{array}{rr}
A & -I \\
-I & B
\end{array}\right]\left[\begin{array}{l}
i \\
i
\end{array}\right]\right)\left[\begin{array}{l}
y^{\prime} \\
y
\end{array}\right] \\
& \quad=\left[\begin{array}{l}
i \\
i
\end{array}\right]\left[\begin{array}{l}
w P^{\prime} \\
w P
\end{array}\right] \ldots \ldots \ldots \ldots \ldots \ldots \ldots \ldots \ldots
\end{aligned}
$$

こうすれば, 左辺係数行列の逆行列を計算することに より連続吊橋の解が得られる。

つぎに, 式 (39) の元数を引下げるため, $\boldsymbol{y}^{\prime}$ を消去 することを考えてみよう。

式 (39) は, $\boldsymbol{y}, \boldsymbol{y}^{\prime}$ を求めるため直接係数行列の逆行 列を求めるのでなければ

$$
\left[\begin{array}{r}
i \\
i
\end{array}\right]\left[\begin{array}{rr}
A & -I \\
-I & B
\end{array}\right]\left[\begin{array}{l}
i \\
i
\end{array}\right]\left[\begin{array}{l}
y^{\prime} \\
y
\end{array}\right]=\left[\begin{array}{l}
i w P^{\prime} \\
i w P
\end{array}\right]
$$

としてよい。すなわち，

$$
\begin{aligned}
& (i+H i w \gamma i) y^{\prime}-i y=i w P^{\prime} \\
& -i y^{\prime}+(i+i w h i) y=i w P
\end{aligned}
$$

ただし， $h=\gamma t^{-1} \gamma$ とする。

これより, 式 (41), (42) を加えて

$$
H i w \boldsymbol{i y}+i w h i y=i w\left(P^{\prime}+P\right)
$$

$\boldsymbol{w}$ は対角行列であるから

$$
H w i \boldsymbol{i y}+w i h i y=w i\left(P^{\prime}+P\right)
$$

したがって,

$$
H \boldsymbol{i} \boldsymbol{\gamma} \boldsymbol{i y}+\boldsymbol{i h i y}=\boldsymbol{i}\left(\boldsymbol{P}^{\prime}+\boldsymbol{P}\right)
$$

式 (42)を(43) に代入して

$$
i+H \boldsymbol{r} i \boldsymbol{w}=\omega
$$

とおけば,

$$
\boldsymbol{i}(H \boldsymbol{r}+\boldsymbol{\omega} h) \boldsymbol{i y}=\boldsymbol{i} \boldsymbol{P}^{\prime}+\boldsymbol{\omega} \boldsymbol{P}
$$

これで $\boldsymbol{y}$ に関する方程式が求まったわけであるが，y の係数行列は正則ではなく，これを正則化するため再び 社を用いて $\boldsymbol{y}$ を表わせば

$$
\boldsymbol{y}=\left\{\boldsymbol{i}^{\prime}+\boldsymbol{i}(H \boldsymbol{\gamma}-\boldsymbol{\omega} \boldsymbol{h}) \boldsymbol{i}\right\}^{-1}\left(\boldsymbol{i} \boldsymbol{P}^{\prime}+\boldsymbol{\omega} \boldsymbol{P}\right)
$$

となる。こうして $\boldsymbol{y}$ が求まれば, $\boldsymbol{y}^{\prime}, \boldsymbol{M}$ は

$$
\begin{aligned}
& y^{\prime}=(i+i w h) y-i w P \\
& M=t^{-1} \boldsymbol{\gamma} y \ldots \ldots \ldots \ldots \ldots
\end{aligned}
$$

として計算すればよい。

なお, 中間支点のない形式では, 曲げモーメント $\boldsymbol{M}$ を末知数にとることもできる。結果のみを記せば，

$$
\begin{aligned}
& \boldsymbol{k}=\boldsymbol{r}+H \boldsymbol{r} \boldsymbol{w} \boldsymbol{\gamma} \\
& \boldsymbol{M}=(H \boldsymbol{t}+\boldsymbol{k})^{-1}\left(\boldsymbol{k} \boldsymbol{M}_{0}+\boldsymbol{P}^{\prime}\right) .
\end{aligned}
$$

$\boldsymbol{M}_{0}: \boldsymbol{P}$ による単純ばりとしての曲げモーメントベク トル

\section{(2) 微分方程式との関連}

式 (38) より

$$
\begin{aligned}
& \boldsymbol{y}^{\prime}+H \boldsymbol{w} \boldsymbol{\gamma}-\boldsymbol{y}=\boldsymbol{w} \boldsymbol{P}^{\prime} \\
& -\boldsymbol{y}^{\prime}+\boldsymbol{y}+\boldsymbol{w h y}=\boldsymbol{w} \boldsymbol{P}
\end{aligned}
$$

式 (42) 第 $i$ 行を展開すれば

$$
\begin{gathered}
y_{i}{ }^{\prime}+\frac{H}{T_{i}} v_{i}\left\{-\frac{1}{d_{i}} y^{\prime}{ }_{i-1}+\left(\frac{1}{d_{i}}+\frac{1}{d_{i+1}}\right) y_{i}{ }^{\prime}\right. \\
\left.-\frac{1}{d_{i+1}} y^{\prime}{ }_{i+1}\right\}-y_{i}=\frac{1}{T_{i}} v_{i} P_{i}{ }^{\prime}
\end{gathered}
$$

$d_{i}$ を一定とすれば，

$$
\begin{gathered}
-H \frac{y^{\prime}{ }_{i-1}-2 y_{i}{ }^{\prime}+y^{\prime}{ }_{i+1}}{d^{2}}-\frac{1}{v_{i}} \frac{T_{i}}{d}\left(y_{i}-y_{i}{ }^{\prime}\right) \\
=\frac{P_{i}^{\prime}}{d} \cdots \cdots \cdots \cdots \cdots \cdots \cdots \cdots \cdots \cdots \cdots \cdots \cdots \cdots \cdots \cdots \cdots \cdots \cdots \cdots \cdots \cdots \cdots \cdots \cdots \cdots
\end{gathered}
$$

また式（48）は，

$$
\begin{array}{r}
-y_{i}{ }^{\prime}+y_{i}+\frac{v_{i}}{T_{i}}\left\{-\frac{1}{d_{i}} M_{i-1}+\left(\frac{1}{d_{i}}+\frac{1}{d_{i+1}}\right) M_{i}\right. \\
\left.-\frac{1}{d_{i+1}} M_{i+1}\right\}=\frac{v_{i}}{T_{i}} P_{i} \\
\therefore \frac{1}{v_{i}} \frac{T_{i}}{d}\left(y_{i}-y_{i}{ }^{\prime}\right)-\frac{M_{i-1}-2 M_{i}+M_{i+1}}{d^{2}}=\frac{P_{i}}{d}
\end{array}
$$

$d \rightarrow 0$ として微分方程式に変換すれば,

$$
-H \frac{d^{2} y^{\prime}}{d x^{2}}-\frac{t}{v}\left(y-y^{\prime}\right)=p^{\prime}
$$




$$
E I \frac{d^{4} y}{d x^{4}}+\frac{t}{v}\left(y-y^{\prime}\right)=p
$$

となる。

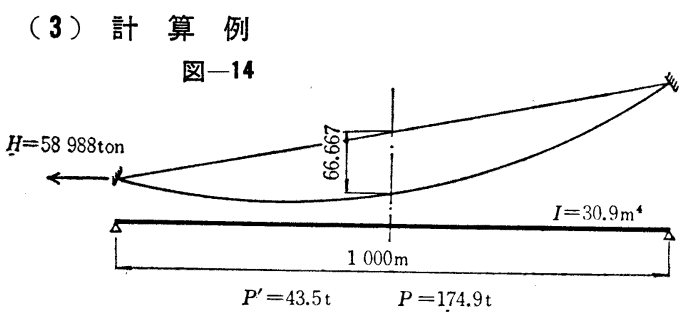

図一15 P, $P^{\prime}$ による曲げモーメント影響值

$20000 \mathrm{t}-\mathrm{m}$

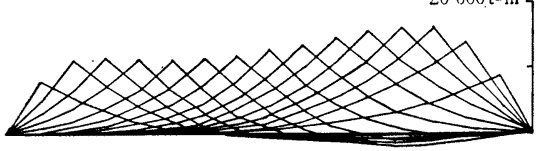

図一16 P, $P^{\prime}$ によるせん断力影響值

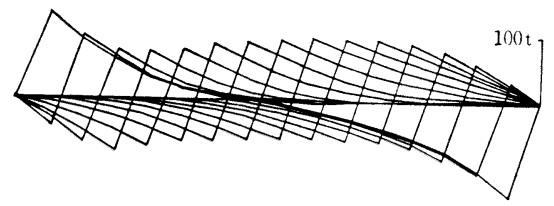

図一17 P, $P^{\prime}$ 㴖輔による曲げモーメント

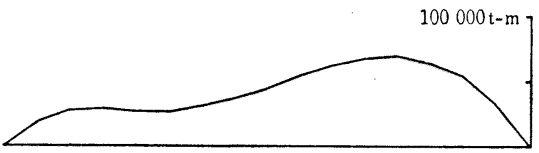

図一18 P, $P^{\prime}$ 滿载による水平変位

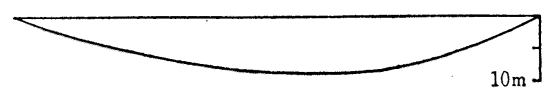

図一19 $P, P^{\prime}$ 㴖栈によるせん断力

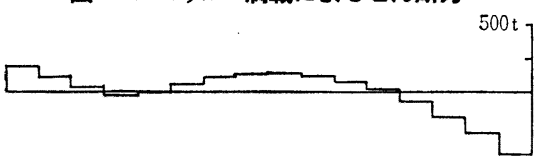

図-20
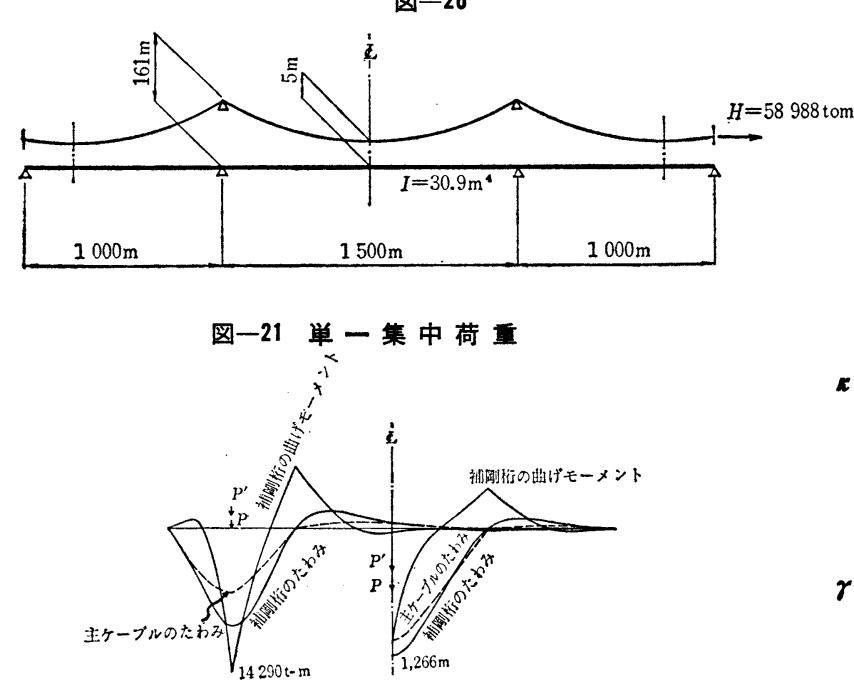

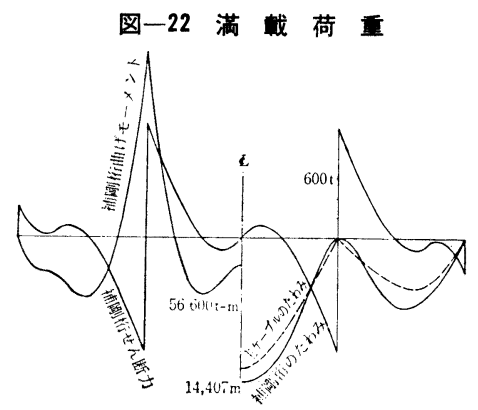

\section{4. 吊橋主塔への応用}

図のように, 主塔に荷重が載荷 図-23 されたときの節点の変位 $x$,曲げモ ーメント $M$ を求めることにする。 $i-1 \sim i$ の軸力を $N_{i}$ とし材軸 の変形による直角分力を $i$ 端にお いて $S_{i, i-1}$ とすれば,

$$
\begin{aligned}
& N_{i}=\sum_{r=0}^{i-1} P_{i}, \quad \kappa_{i}=\frac{N_{i}}{l_{i}} \\
& S_{i, i-1}=\kappa_{i}\left(x_{i-1}-x_{i}\right)
\end{aligned}
$$

$i$ 点におけるせん断力のつりあ いより

$$
\begin{aligned}
& -\gamma_{i} M_{i-1}+\left(\gamma_{i}+r_{i+1}\right) M_{i}-\gamma_{i+1} M_{i+1}-\kappa_{i} x_{i-1} \\
& \quad+\left(\kappa_{i}+\kappa_{i+1}\right) x_{i}-\kappa_{i+1} x_{i+1}=-H_{i} \cdots \cdots \cdots \cdots
\end{aligned}
$$

たわみと曲げモーメントの関係より

$$
\begin{aligned}
& t_{i} M_{i-1}+2\left(t_{i}+t_{i+1}\right) M_{i}+t_{i+1} M_{i+1}-\gamma_{i} x_{i-1} \\
& \quad+\left(r_{i}+r_{i+1}\right) x_{i}-\gamma_{i+1} x_{i+1}=0 \ldots \ldots \ldots \ldots \ldots \ldots
\end{aligned}
$$

ここで,

$$
\begin{gathered}
\boldsymbol{M}=\left(\begin{array}{l}
M_{1} \\
M_{2} \\
\cdots \\
M_{n}
\end{array}\right), \quad \boldsymbol{x}=\left(\begin{array}{l}
x_{0} \\
x_{1} \\
\cdots \\
x_{n-1}
\end{array}\right), \quad \boldsymbol{H}=\left(\begin{array}{l}
H_{0} \\
H_{1} \\
\cdots \\
H_{n-1}
\end{array}\right) \\
t_{i}=\frac{l_{i}}{6 E I_{i}}, \quad r_{i}=\frac{1}{l_{i}}
\end{gathered}
$$

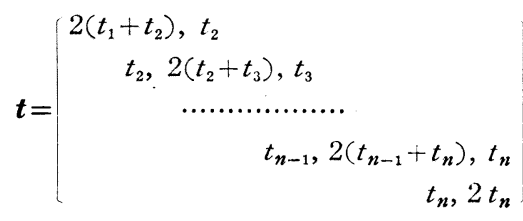

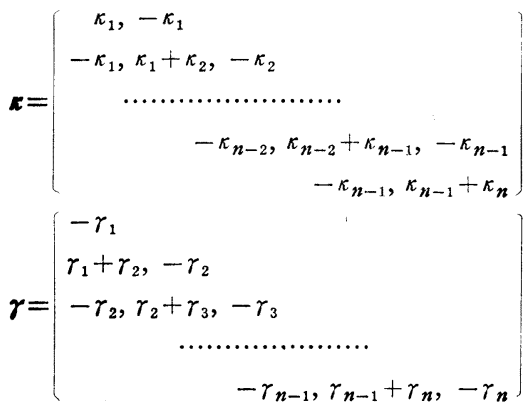


とおけばつぎのように表わすことができる。

$\boldsymbol{c} \boldsymbol{x}+\boldsymbol{\gamma} \boldsymbol{M}=-\boldsymbol{H}$

$r^{*} x+t M=0$

したがって，

$$
\boldsymbol{M}=\left(\boldsymbol{t}-\boldsymbol{\gamma}^{*} \boldsymbol{\kappa}^{-1} \boldsymbol{\gamma}\right)^{-1} \boldsymbol{\gamma}^{*} \boldsymbol{\kappa}^{-1} \boldsymbol{H}
$$

$$
\boldsymbol{x}=-\boldsymbol{x}^{-1}(\boldsymbol{\gamma} \boldsymbol{M}+\boldsymbol{H}) \cdots(60)
$$

となる。図のような最も単純な場合 を例にとれば,

$$
\begin{aligned}
& M=-H l-P x \\
& x=\frac{l^{3}}{3 E I-P l^{2}} H
\end{aligned}
$$

$3 E I=P l^{2}$ の場合には解は存在し ない。これは $H=0$ でない限り, 変

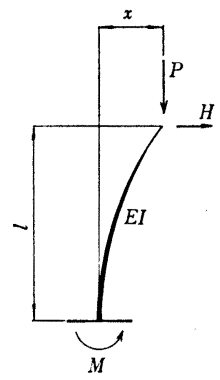

形は無限大となることを意味し, $3 E I<P l^{2}$ のときは, $H$ と $x$ はたがいに逆向きとなる。

このように, 式（59）においても $\boldsymbol{t}-\boldsymbol{\gamma}^{*} \boldsymbol{\pi}^{-1} \boldsymbol{\gamma}$ の行列 式が 0 に近くなると吊橋本体に与える拘束力は非常に小 さくなる。

そしてまた，そのような状態が最も望ましいものでも ある。

なお, 式 (57), (58) の微分方程式に変換すれば, 式 (58) は,たわみ角とたわみとの関係式に, 式 (57) は, つぎのようになる。

$$
E I \frac{d^{4} x}{d v^{4}}+P \frac{d^{2} x}{d v^{2}}=0
$$

これに境界条件を入れて解き $P$ を求めれば, 図一25 の中央の場合の解が求まるわけである。すなわち,

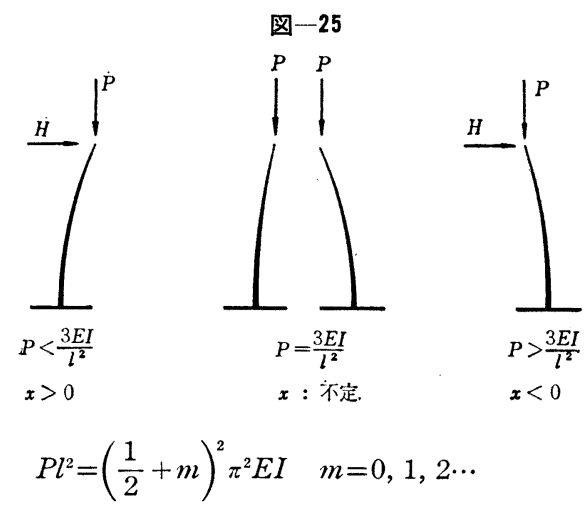

$P$ の最小值は,

$$
P l^{2}=2.4674 E I
$$

之なる。前に求めた解が $P l^{2}=3 E I$ となっているのは,途 中に節点を考えなかったためで，実際には $x$ が不定とな る解は, 節点の数にしたがって増えその $P$ の最小值は, 微分方程式による解に急速に近ゔいていくことになる。

すなわち, 節点数 $n=2,3$ の場合を示せば, $P l^{2}=$ $2.6353 E I, P l^{2}=2.4901 E I$ となる

逆に塔頂の変位 $x_{0}$ が与えられ, これに対して塔頂水
平力, 各節点の変位, 曲げモーメントを求める場合があ る。

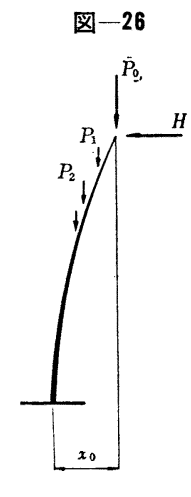

このときは,レダクション法を用 いるのが便利である。結果のみを記 せばつぎのようになる。

$$
\begin{aligned}
N_{i} & =\sum_{r=0}^{r=i-1} P_{i} \\
s_{i} & =\frac{6 E I_{i} l_{i}}{6 E I_{i}+l_{i}{ }^{2} N_{i}} \\
t_{i} & =\frac{3 l_{i}{ }^{2}}{6 E I_{i}+l_{i}{ }^{2} N_{i}} \\
u_{i} & =\frac{l_{i}{ }^{3}}{6 E I_{i}+l_{i}{ }^{2} N_{i}} \\
s_{i}{ }^{\prime} & =1-\frac{l_{i} N_{i}}{2 E I_{i}} s_{i}, \quad t_{i}{ }^{\prime}=\frac{l_{i}}{E I_{i}}-\frac{l_{i} N_{i}}{2 E I_{i}} t_{i} \\
u_{i}{ }^{\prime} & =\frac{l^{2}}{2 E I_{i}}-\frac{l_{i} N_{i}}{2 E I_{i}} u_{i}
\end{aligned}
$$

とおけば, $i$ 点のたわみ, たわみ角, 曲げモーメントは,

$$
\left(\begin{array}{l}
x_{i} \\
\theta_{i} \\
M_{i} \\
H
\end{array}\right)=\left(\begin{array}{cccc}
1, & s_{i}, & -t_{i} & u_{i} \\
s_{i}{ }^{\prime}, & -t_{i}{ }^{\prime}, & u_{i}{ }^{\prime} \\
N_{i} s_{i}, & 1-t_{i}, & N_{i} u_{i}-l_{i} \\
& & 1
\end{array}\right)\left(\begin{array}{l}
x_{i-1} \\
\theta_{i-1} \\
M_{i-1} \\
H
\end{array}\right) \cdots
$$

これを

$$
W_{i}=F_{i} W_{i-1}
$$

と表わせば,

$$
\boldsymbol{W}_{n}=\boldsymbol{F}_{n} \cdot \boldsymbol{F}_{n-1} \cdot \boldsymbol{F}_{n-2} \cdots \boldsymbol{F}_{2} \cdot \boldsymbol{F}_{1} \cdot \boldsymbol{W}_{0}=\boldsymbol{F} \boldsymbol{W}_{0} \cdots
$$

ここで

$$
\boldsymbol{F}=\left(\begin{array}{cccc}
f_{11} & f_{12} & f_{13} & f_{14} \\
f_{21} & f_{22} & f_{23} & f_{24} \\
f_{31} & f_{32} & f_{33} & f_{34} \\
& & & 1
\end{array}\right)
$$

とおけば, $\boldsymbol{W}_{0}$ の中の未知要素は,

$$
\left[\begin{array}{c}
\theta_{0} \\
H
\end{array}\right]=\left[\begin{array}{cc}
f_{12}, & f_{14} \\
f_{22}, & f_{24}
\end{array}\right]^{-1}\left[\begin{array}{c}
x_{0} \\
0
\end{array}\right]
$$

より求まる。

\section{5. tri-diagonal matrix の逆行列について}

以上の各章に限らず, 構造物の行列解析において, tri-diagonal matrix の逆行列を求めることが非常にし ばしば生じる。したがってこの逆行列の簡単な計算法を 知っておくと便利であるし，また，この方法をサブルー チンとしてプログラムしておけばいろいろ利用法もある と思う。以下に筆者の用いている方法を説明する。

一般形として,

$$
\boldsymbol{D}=\left(\begin{array}{lllll}
a_{1} & b_{1} & & \\
b_{1}^{\prime} & a_{2} & b_{2} & \\
& b_{2}^{\prime} & a_{3} & b_{3} \\
& & \cdots \cdots \cdots . . . \\
& & & b^{\prime}{ }_{n-1} a_{n}
\end{array}\right)
$$




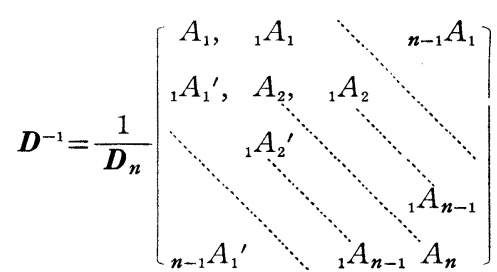

とおく行列式 $D_{n}$ を構成する小行列式を下のように， $D_{n}$ の上からの小行列式を $D_{1}, D_{2} \cdots D_{n}$ 下からの小行列 式

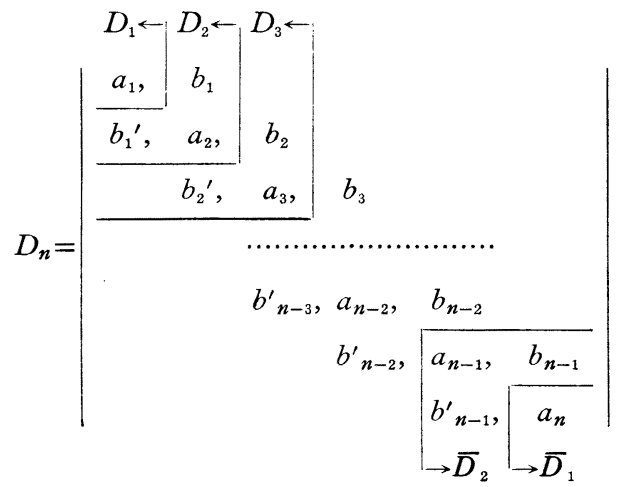

を $\bar{D}_{1}, \bar{D}_{2}, \cdots, \bar{D}_{m}$ とすれば，これらは順次つぎのよう

にして求めることができる。

$$
\begin{aligned}
& D_{1}=a_{1} \\
& D_{2}=a_{2} D_{1}-b_{1} b_{1}{ }^{\prime} D_{0} \\
& D_{i}=a_{i} D_{i-1}-b_{i-1} b^{\prime}{ }_{i-1} D_{i-2} \\
& D_{n}=a_{n} D_{n-1}-b_{n-1} b^{\prime}{ }_{n-1} D_{n-2} \\
& \bar{D}_{1}=a_{n} \\
& \bar{D}_{2}=a_{n-1} \bar{D}_{1}-b_{n-1} b^{\prime}{ }_{n-1} \bar{D}_{0} \\
& \bar{D}_{i}=a_{n-i+1} \bar{D}_{i-1}-b_{n-i} b^{\prime}{ }_{n-i+1} \bar{D}_{i-2} \\
& \bar{D}_{n}=a_{1} \bar{D}_{n-1}-b_{1} b_{1}{ }^{\prime} \bar{D}_{n-2}
\end{aligned}
$$

ただし $D_{0}=\bar{D}_{0}=1$ とする。 さらに,

$$
\begin{array}{rl}
A_{i}=D_{i-1} \bar{D}_{n-i} & i=1,2, \cdots n \\
{ }_{1} A_{i}=-D_{i-1} b_{i} \bar{D}_{n-i+1} & i=1,2, \cdots n-1 \\
{ }_{2} A_{i}=D_{i-1} b_{i} b_{i+1} \bar{D}_{n-i+2} & i=1,2, \cdots n-2 \\
\cdots \cdots \cdots \cdots \cdots \cdots \cdots \cdots \cdots \cdots \cdots \cdots \cdots \cdots \cdots & \\
{ }_{j} A_{i}=(-1)^{j} D_{i-1} b_{i} b_{i+1} \cdots b_{i+j-1} \bar{D}_{n-i-j} & i=1,2, \cdots n-j
\end{array}
$$$$
{ }_{n-1} A_{i}=(-1)^{n-1} b_{1} b_{2} \cdots b_{n-1} \quad i=1
$$

また ${ }_{j} A_{i}{ }^{\prime}$ は上において $b_{i} \rightarrow b_{i}{ }^{\prime}$ とするとよい。

\section{6. 結言}

以上有限変形法を応用した行列による吊橋の解析につ いて説明したが，2., 3. については，すでに，伊藤忠電 子計算センター, CDC 3600 を対象にプログラムが完成 されている。

また, 本理論は, 架設中の吊橋など, 微小変形理論で は不安定架構となるような構造物の解析に対しても, き わめて有力な手段となり得る。

わが国においても，本格的な大型電子計算機の普及が. いちじるしい現在，既往の理論よりも，正確かつ迅速な 解析手段として十分な利用価值があるものと信ずる。

\section{参 考 文献}

1) J. Melan : Theorie der eisernen Bogenbrücken und Hängebrücken. 平井 敦：鋼橋 III 技報堂.

2) L.S. Moisseiff, Frederick Lienhard : Suspension Bridges under the Action of Lateral Forces Trans. ASCE, Vol. 98.

3) C.A. Erzen : Lateral Bending of Suspension Bridges. Proc. ASCE, Vol. 81 Separate, No. 663.

4) 後藤茂夫：不規則吊材を有する吊橋の解法, 橋梁構造工学研究発表会, 1964.

(1967.11.2 ·受付) 